Check for updates

Cite this: Mater. Adv., 2020,

1,2206

Received 14th July 2020,

Accepted 26th August 2020

DOI: $10.1039 / \mathrm{d} 0 \mathrm{ma} 00508 \mathrm{~h}$

rsc.li/materials-advances

\section{Suppressing vanadium crossover using sulfonated aromatic ion exchange membranes for high performance flow batteries $\dagger$}

\author{
Tongshuai Wang, ${ }^{a}$ Junyoung Han, ${ }^{\mathrm{b}}$ Kihyun Kim, ${ }^{\mathrm{b}}$ Andreas Münchinger, ${ }^{\mathrm{c}}$ \\ Yuechen Gao, ${ }^{a}$ Alain Farchi, ${ }^{d}$ Yoong-Kee Choe, ${ }^{e}$ Klaus-Dieter Kreuer, ${ }^{* c}$ \\ Chulsung Bae ${ }^{* b}$ and Sangil Kim (D) *a
}

Liquid flow batteries have potential to achieve high energy efficiency as a large-scale energy storage system. However, the ion exchange membranes (IEMs) currently used in flow batteries do not have high ion selectivity and conductance at the same time, owing to the tradeoff between ionic membrane resistance and ion selectivity. Here, we report a rationally designed sulfonated aromatic polymer membrane which can greatly mitigate the trade-off limitation and achieve high performance vanadium RFB. Small-angle X-ray scattering studies and density functional theory calculations indicated that the narrowly distributed aqueous ionic domain of just the right width $(<7 \AA)$ and the strong hydrogen bond interaction of vanadium species with a unique polymer side chain structure play a key role in improving the ion selectivity. Our systematic studies of the polymer structures, morphologies, and transport properties provide valuable insight that can aid in elucidating the structure-property relationship of IEMs and in establishing design criteria for the development of highperformance membranes.

\section{Introduction}

Membrane-based electrochemical devices have shown great potential for use in many next-generation energy conversion and storage systems, such as fuel cells, ${ }^{1}$ redox flow batteries, ${ }^{2,3}$ and reverse electrodialysis, ${ }^{4}$ owing to their high energy efficiency and large-scale adaptability. For a broader application of these technologies, ion exchange membranes (IEMs) with high

\footnotetext{
${ }^{a}$ Department of Chemical Engineering, University of Illinois at Chicago, Chicago,

IL 60607, USA. E-mail: sikim@uic.edu

${ }^{b}$ Department of Chemistry \& Chemical Biology, Department of Chemical \& Biological Engineering, Rensselaer Polytechnic Institute, Troy, NY 12180, USA. E-mail: baec@rpi.edu

${ }^{c}$ Max-Planck-Institute for Solid State Research, Heisenbergstrasse 1, 70569 Stuttgart, Germany. E-mail: kreuer@fkf.mpg.de

${ }^{d}$ Université Grenoble Alpes, CEA, IRIG-DEPHY-MEM, 38000 Grenoble, France

${ }^{e}$ National Institute of Advanced Industrial Science and Technology, Tsukuba, Japan

$\dagger$ Electronic supplementary information (ESI) available. See DOI: 10.1039/d0ma00508h
}

ion conductivity and selectivity properties are critical for enhancing the electrochemical performance of electrolyte cells. Conventional polymeric IEMs, however, suffer from the trade-off between ion conductivity (membrane resistance) and selectivity of co/counter-ions and fuels, which greatly reduces the efficiency of energy conversion and storage systems. ${ }^{5,6}$

Among energy storage systems, vanadium redox flow batteries (VRFBs) have been recognized as one of the most promising technologies for grid-scale energy storage, owing to excellent design flexibility and safety, benefited from their decoupled energy storage and power generation. ${ }^{7-11}$ By using vanadium ions as the active species in both catholyte and anolyte solutions, VRFBs eliminate the risk of detrimental cross-contamination effects, thus greatly improving their service life. ${ }^{12,13}$ As a key component in VRFBs, IEMs should have low vanadium permeability for the separation of the vanadium species in the catholyte and anolyte solutions while allowing selective transport of charge-carrier ions with high ionic conductivity. ${ }^{14}$ Unfortunately, most of the cation exchange membranes (CEMs) do not meet these criteria, owing to their intrinsic trade-off between proton conductance and the selectivity of protons over vanadium ions $\left(\mathrm{H}^{+} / \mathrm{V}^{n+}\right)$, thus hampering the widespread implementation of VRFBs. For instance, although Nafion ${ }^{\circledR}$, a perfluorosulfonated polymer CEM, is commonly used in VRFBs because of its high proton conductivity, chemical stability, and commercial availability, the high vanadium permeability of the Nafion ${ }^{\circledR}$ membrane causes undesired coulombic efficiency (CE) drop and fast capacity decay. ${ }^{14-16}$ To minimize the crossover of vanadium ions, a thicker Nafion membrane (e.g., Nafion 117) has to be employed at the expense of higher membrane resistance, raising the VRFB stack cost. Currently, Nafion membranes account for $40 \%$ of the total cost of a VRFB cell stack. ${ }^{17}$ To overcome the limitations of Nafion membranes, extensive efforts have been made to improve ion selectivity by introducing ion selective surface coatings ${ }^{18}$ or inorganic fillers, such as $\mathrm{SiO}_{2},{ }^{19} \mathrm{TiO}_{2},{ }^{20}$ and $\mathrm{ZrO}_{2}{ }^{21,22}$ Although the modified Nafion membranes show 
a suppressed vanadium permeability, the additives can cause adverse effect of higher cell resistance, which does not help to overcome the trade-off limitation. ${ }^{14}$ Alternatively, hydrocarbonbased anion exchange membranes (AEMs) ${ }^{23}$ have been investigated for VRFBs because of their cation (e.g. vanadyl cation) exclusion effect (Donnan exclusion). However, in highly concentrated electrolytes of VRFBs (typically $\geq 3 \mathrm{M}$ ), the Donnan exclusion effect is weak and cannot compensate for the lower ion conductivity of typical AEMs compared to Nafion. As a consequence, the decrease in voltage efficiency (VE) and energy efficiency (EE) makes AEMs less appealing for VRFB applications at high current densities. ${ }^{24}$ Recently, a polyamide thinfilm composite membrane exhibited an EE of VRFB greater than $80 \%$ at $260 \mathrm{~mA} \mathrm{~cm} \mathrm{~cm}^{-2}$ by optimizing the thickness of the polyamide selective layer. ${ }^{25}$ However, the polyamide membrane still exhibits the trade-off limitation. Furthermore, the amide bonds in polyamide are known to be susceptible to hydrolysis which could result in stability issues under strong acidic

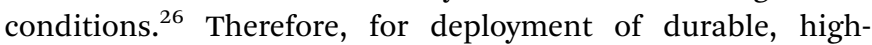
performance VRFB systems, the design and fabrication of advanced IEMs, which can overcome the intrinsic trade-off limitations, via the optimization of various parameters at molecular levels (e.g. ionic group, ion exchange capacity, and aqueous ionic domain width) is highly critical.

In this paper, we report a novel class of sulfonated aromatic polymer CEMs and demonstrate their superior battery performance in achieving both high VE and high CE and overcoming the trade-off limitation barrier of IEMs. To establish the relationship between the molecular structures and the selective ion transport properties, we rationally designed a series of polymers composed of a biphenyl backbone with different side chains (Fig. 1a). Among the polymers investigated, the biphenyl polymer with the longest side chain containing an additional aromatic ring and a perfluorinated segment (BP-ArF4 of Fig. 1a) exhibited good proton conductivity while also maintaining extraordinary high proton/vanadium ion selectivity. The unique feature of this ionic polymer includes a hydrophobic/hydrophilic separation on a small length scale typical of hydrocarbons with a high degree of order and the super-acidity characteristic typical of perfluorosulfonate ionomers. The unique combination of these characteristics affords BP-ArF4 a remarkable battery performance (CE 99\%, EE up to $93.9 \%$ ) exceeding that of all other IEMs in VRFB applications. Small-angle X-ray scattering (SAXS) and density functional theory (DFT) calculations provide a semi-quantitative understanding of the observed performance.

\section{Results and discussion}

\section{Polymer synthesis and characterization}

As shown in Fig. S1 (ESI $\dagger$ ), three examples of cation exchange polymers (BP-SA, BP-ArSA, and BP-ArF4) were prepared from the biphenyl polymer precursor BPBr-100, which has a bromoalkyl group on the side chain. For BP-SA, the brominated side chain of the precursor polymer was replaced with $-\mathrm{SO}_{3} \mathrm{H}$,
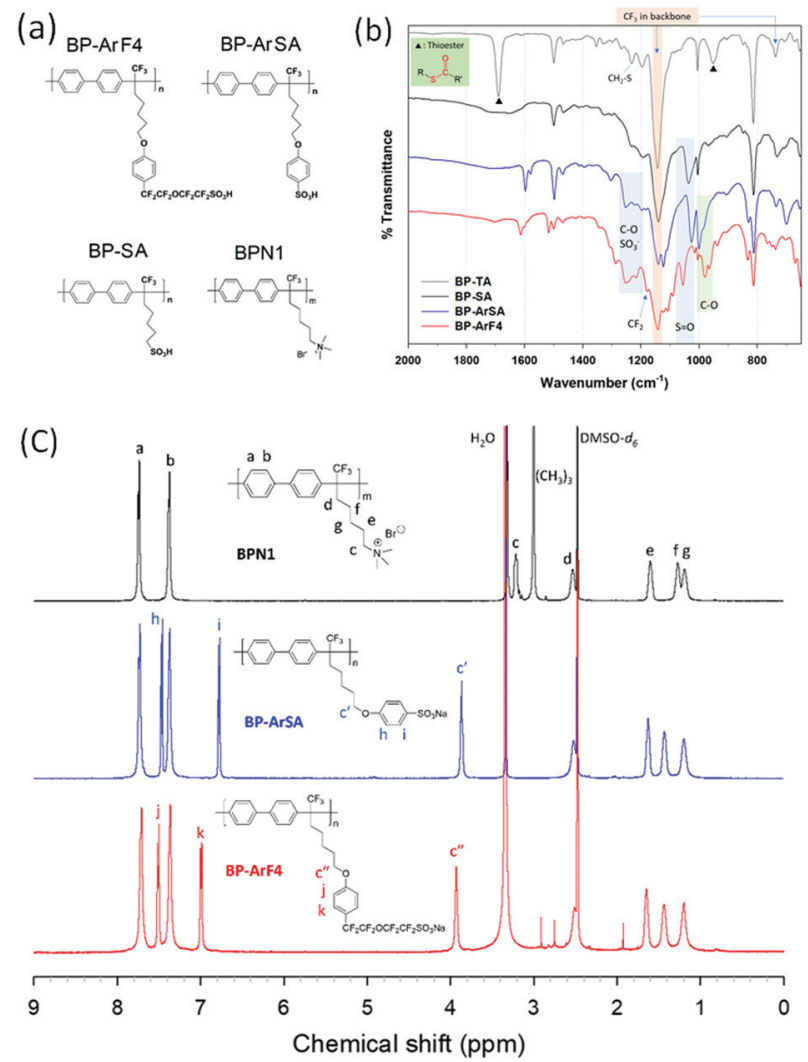

Fig. 1 Chemical structures and FT-IR spectra of the synthesized polymers. (a) Chemical structures of the polymers. (b) FT-IR spectra of the synthesized BP-TA (gray) and cation exchange polymers: BP-SA (black), BP-ArSA (blue), and BP-ArF4 (red). (c) ${ }^{1} \mathrm{H}$ NMR spectra (DMSO- $d_{6}$ ) of the synthesized polymers: BPN1 (black), BP-ArSA ( $\mathrm{Na}$ salt form, blue), and BP-ArF4 (red; the peaks at 1.96, 2.78, and 2.94 ppm are from residual DMAc solvent from solvent casting).

and it has the shortest side chain, with a flexible $-\left(\mathrm{CH}_{2}\right)_{5}-$ spacer between the backbone and sulfonate group, among the three investigated CEMs. BP-ArSA has an additional aromatic ring in the sulfonate side chain, while BP-ArF4 contains a perfluoroalkylsulfonate group in addition to an aromatic ring in the side chain. As all three sulfonated polymers share the same biphenyl backbone structure and were prepared from the precursor polymer BPBr-100, they should have no difference in molecular weight. The difference in properties of these polymers should be derived only from the side chain structures. Through the minor differences in the side chain structures, we studied how they could impact ion conductivity and vanadium ion permeability, which can be translated to battery efficiencies. We also prepared BPN1, an AEM counterpart of BP-SA, from $\mathrm{BPBr}-100$ to study the effect of sulfonate $v s$. quaternary ammonium side chains on membrane properties and battery performance.

Because BP-SA has poor solubility in organic solvents, BP-SA membranes were prepared by the oxidation of BP-TA film (Fig. S1, ESI $\dagger$ ). BP-TA was prepared via a nucleophilic substitution reaction of $\mathrm{BPBr}-100$ and potassium thioacetate; whereafter, it was cast into a film and immersed in a hydrogen 
peroxide solution for the oxidation of $-\mathrm{SC}(=\mathrm{O}) \mathrm{CH}_{3}$ of BP-TA to $-\mathrm{SO}_{3} \mathrm{H}$ of BP-SA. ${ }^{27}$ Successful conversion to a sulfonic acid group in BP-SA was confirmed using FT-IR spectroscopy and titrated ion exchange capacity (IEC) (Fig. 1b), in which the thioester $\mathrm{S}-(\mathrm{C}=\mathrm{O})-\mathrm{C}$ stretching bands of BP-TA at 1690 and $952 \mathrm{~cm}^{-1}$ disappeared, and the $\mathrm{S}=\mathrm{O}$ stretching bands of $-\mathrm{SO}_{3} \mathrm{H}$ in BP-SA were clearly visible at 1200 and $1037 \mathrm{~cm}^{-1}$. BP-ArSA was synthesized using a one-step nucleophilic substitution of $\mathrm{BP}-\mathrm{Br}$ with sodium 4-hydroxybenzenesulfonate, as shown in Fig. S1 (ESI $\dagger$ ). Because BP-ArSA (in $-\mathrm{SO}_{3} \mathrm{Na}$ form) is soluble in DMSO, the chemical structure of BP-ArSA was confirmed using ${ }^{1} \mathrm{H}$ NMR and FT-IR spectroscopies (Fig. 1c). In addition to $\mathrm{S}=\mathrm{O}$ stretching bands at 1220 and $1026 \mathrm{~cm}^{-1}, \mathrm{C}-\mathrm{O}$ stretching bands were observed at 1252 and $1000 \mathrm{~cm}^{-1}$ in the FT-IR spectrum. To synthesize BP-ArF4, we first synthesized BP-Ar-I via the nucleophilic substitution of BPBr-100 with 4-indophenol and then subjected the aryl iodide in the polymer pendant chain to Ullmann coupling reaction with compound 1 (Fig. S1, ESI $\dagger$ ). Structural characterization of BP-ArF4 was confirmed using ${ }^{1} \mathrm{H}$ and ${ }^{19} \mathrm{~F}$ NMR (in $-\mathrm{SO}_{3} \mathrm{Na}$ form) and FT-IR (in $-\mathrm{SO}_{3} \mathrm{H}$ form) spectroscopies (Fig. S1 and S3, ESI $\dagger$ ). The FT-IR spectrum showed the presence of $-\mathrm{SO}_{3} \mathrm{H}(\mathrm{S}=\mathrm{O}$ stretching bands at 1216 and $1056 \mathrm{~cm}^{-1}$ ), aryl ether bonds (C-O stretching bands at 1251 and $1090 \mathrm{~cm}^{-1}$ ), and a perfluoroalkyl ether moiety $\left(\mathrm{CF}_{2}-\mathrm{O}\right.$ stretching at $\left.980-960 \mathrm{~cm}^{-1}\right)$. BPN1 was prepared by following the procedure mentioned in our previous report. ${ }^{28}$

\section{Ion transport properties}

To characterize the ion transport properties of the membranes, we evaluated the IEC, vanadium ion permeability, proton conductivity, and area resistance of the prepared membranes (Table 1). Commercial Nafion 117 and Nafion 212 membranes, which are widely used in VRFBs, were used as reference samples. Low vanadium ion crossover is a critical property of IEMs to achieve high CE and low capacity loss for VRFB applications. Among all evaluated CEMs, BP-SA showed the highest vanadium permeability of $110.1 \times 10^{-7} \mathrm{~cm}^{2} \mathrm{~min}^{-1}$ possibly due to the highest IEC and swelling ratio. In comparison, BP-ArSA exhibited a markedly lower vanadium permeability of $13.5 \times 10^{-7} \mathrm{~cm}^{2} \mathrm{~min}^{-1}$, thus indicating that the incorporation of an aromatic group and an ether linkage in the side chain can greatly improve the vanadium ion rejection property of the membrane. BP-ArF4 with an additional perfluoroalkyl pendant chain further suppressed the vanadium ion permeability to $10.2 \times 10^{-7} \mathrm{~cm}^{2} \mathrm{~min}^{-1}$, a value 4.0 times and 3.2 times lower than those for Nafion 212 and Nafion 117, respectively. Hydrated vanadium ion and proton transports in the sulfonated aromatic polymers have been found to be heavily affected by the dimension of the separated hydrophobic and hydrophilic domains in the microstructures. ${ }^{29}$ In general, swelling ratio values are closely related to water uptake and, in Table 1, we use the swelling ratio to correlate the dimensional stabilities of membranes with ion selectivity. The swelling ratios for BP-ArSA (12.9\%) and BP-ArF4 (10.2\%) were significantly lower than that of BP-SA (18.6\%), suggesting a smaller aqueous domain within the polymer matrix in spite of the same backbone structure of all three biphenyl CEMs. We also tested BPN1, an AEM with the identical molecular structure of BP-SA, to investigate the structure-membrane property relationship of sulfonate $v s$. quaternary ammonium side chains in aromatic polymers. Although BPN1 and BP-SA have comparable linear swelling ratios, BPN1 exhibited a significantly lower vanadium permeability $\left(23.8 \times 10^{-7} \mathrm{~cm}^{2} \mathrm{~min}^{-1}\right)$. This is most likely because the highly concentrated positive quaternary ammonium functional groups of BPN1 AEM impede the transport of the multi-valent vanadium cations as a result of the Donnan exclusion. ${ }^{30,31}$

As the length of the side chain increases in the biphenyl polymer series, their IECs decrease due to lower ion exchange groups $\left(-\mathrm{SO}_{3} \mathrm{H}\right)$ in unit mass (volume): BP-SA (2.29 meq. $\mathrm{g}^{-1}$ ), BP-ArSA (2.01 meq. $\left.\mathrm{g}^{-1}\right)$, and BP-ArF4 (1.25 meq. $\mathrm{g}^{-1}$ ). As expected, the proton conductivity of the CEMs follows the order of IEC: BP-ArF4 < BP-ArSA < BP-SA (Table 1). The proton conductivities of BP-ArSA and BP-ArF4 were 67.6 and $55.3 \mathrm{mS} \mathrm{cm}^{-1}$, respectively, which are comparable to that of Nafion 117 $\left(59.2 \mathrm{mS} \mathrm{cm}^{-1}\right)$ and Nafion $212\left(73.5 \mathrm{mS} \mathrm{cm}^{-1}\right)$. BP-SA showed the highest proton conductivity $\left(94.4 \mathrm{mS} \mathrm{cm}^{-1}\right)$ among all studied CEMs as shown in Table 1 due to the highest IEC.

We defined the ion selectivity $(\alpha)$ of the membranes as the ratio of proton conductivity and vanadium permeability, and the values are listed in Table 1. Although BP-ArF4 and BP-ArSA have a lower IEC and lower proton conductivity than BP-SA, their ion selectivity values were almost seven times higher than that of BPSA. This result suggests that the positive contributions from lower swelling (hydration number) and vanadium permeability due to the incorporation of an aromatic ring and additional perfluoroalkyl moiety in the flexible side chain of the polymers far outweigh the decreases in IEC and ion conductivity. In spite of

Table 1 IEC, $\mathrm{VO}^{2+}$ permeability, proton conductivity, ion selectivity, area resistance, and linear swelling ratio of the membranes

\begin{tabular}{|c|c|c|c|c|c|c|c|}
\hline Samples & $\begin{array}{l}\text { Thickness } \\
(\mu \mathrm{m})\end{array}$ & IEC (meq. $\left.g^{-1}\right)$ & $\begin{array}{l}\mathrm{VO}^{2+} \text { permeability } \\
\left(\times 10^{-7} \mathrm{~cm}^{2} \mathrm{~min}^{-1}\right)\end{array}$ & $\begin{array}{l}\text { Ionic conductivity } \\
\left(\mathrm{mS} \mathrm{cm}^{-1}\right)\end{array}$ & $\left(\times 10^{4} \operatorname{min~S~cm}^{-3}\right)$ & $\begin{array}{l}\text { Area } \\
\text { resistance } \\
\left(\Omega \mathrm{cm}^{2}\right)\end{array}$ & $\begin{array}{l}\text { Linear swelling } \\
\text { ratio (\%) }\end{array}$ \\
\hline BP-ArF4 & $88 \pm 1$ & $1.25 \pm 0.05$ & $10.2 \pm 0.8$ & $55.3 \pm 1.2^{a}$ & 5.42 & $0.28 \pm 0.02$ & 10.2 \\
\hline BP-ArSA & $90 \pm 1$ & $2.01 \pm 0.06$ & $13.5 \pm 0.5$ & $67.6 \pm 0.9^{a}$ & 5.08 & $0.26 \pm 0.02$ & 12.9 \\
\hline BP-SA & $60 \pm 2$ & $2.29 \pm 0.19$ & $110.1 \pm 2.5$ & $94.4 \pm 2.1^{a}$ & 0.75 & $0.23 \pm 0.01$ & 18.6 \\
\hline BPN1 & $97 \pm 2$ & $2.60 \pm 0.05$ & $23.8 \pm 3.4$ & $14.5 \pm 1.4^{b}$ & 0.61 & $0.67 \pm 0.07$ & 17.4 \\
\hline Nafion 212 & $55 \pm 1$ & $0.90 \pm 0.02$ & $41.2 \pm 2.0$ & $73.5 \pm 3.1^{a}$ & 1.78 & $0.23 \pm 0.05$ & 14.3 \\
\hline Nafion 117 & $195 \pm 1$ & $0.89 \pm 0.02$ & $32.1 \pm 1.7$ & $59.2 \pm 2.2^{a}$ & 1.84 & $0.89 \pm 0.09$ & 15.1 \\
\hline
\end{tabular}

${ }^{a}$ Refers to proton conductivity. ${ }^{b}$ Refers to anion conductivity. 
lower proton conductivity, the ion selectivity of BP-ArF4 is more than three times higher than those of Nafion 212 and Nafion 117. Areal specific resistance (ASR) of the membranes was measured using electrochemical impedance spectroscopy (Table 1). The ASR of BPN1 $\left(0.67 \Omega \mathrm{cm}^{2}\right)$ was measured for $\mathrm{SO}_{4}{ }^{2-}$ anion transport of the AEM. Owing to the intrinsically low mobility of $\mathrm{SO}_{4}{ }^{2-}$ anions $\left(8.27 \times 10^{-8} \mathrm{~m}^{2} \mathrm{~s}^{-1} \mathrm{~V}^{-1}\right)$ in aqueous solution, which is approximately one-fourth the proton mobility, ${ }^{32}$ the ASR of BPN1 was significantly higher than those of biphenyl CEMs with a similar thickness. Although the thickness of BP-ArF4 and BP-ArSA membranes (approximately $90 \mu \mathrm{m}$ ) was higher than that of Nafion $212(55 \mu \mathrm{m})$, they all showed comparable ASR values in the range of $0.23-0.28 \Omega \mathrm{cm}^{2}$. These ASR values were significantly lower than that of Nafion $117\left(0.89 \Omega \mathrm{cm}^{2}\right)$, the standard CEM in VRFB with a thickness of $195 \mu \mathrm{m}$ to minimize vanadium ion crossover in the membrane.

\section{VRFB performance}

Fig. 2a-c illustrate VRFB single cell tests with various membrane separators. Among all membranes evaluated, BP-ArF4 showed the best overall performance far exceeding Nafion 117, the most commonly used benchmark separator membrane. Because the transport of vanadium species may occur through diffusional processes even in the absence of current, coulombic losses are expected to dominate at low current density, whereas VE is expected to decrease with increasing charging/discharging current, owing to the charge transfer overpotential and transport resistance within the anolyte, catholyte, and membrane (Fig. 2a and b). As listed in Table 1, Nafion 212, BP-SA, BP-ArSA, and BPArF4 have similar ranges of ASR $\left(0.23-0.28 \Omega \mathrm{cm}^{2}\right)$, and thus they all exhibited higher VE than the thicker Nafion $117(195 \mu \mathrm{m}$ thick, $0.89 \Omega \mathrm{cm}^{2}$ ASR). It was found that, although BP-SA has a smaller ASR than BPN1, the VE of BP-SA is lower than BPN1. The unexpected low VE of BP-SA is presumably due to the voltage loss that resulted from the fast crossover of active species. ${ }^{33}$ The effect of enhanced ion selectivity of BP-ArF4 on VRFB performance was clearly visible in CE. Among all tested membranes, the CE of VRFBs with the BP-ArF4 membrane approached $100 \%$ at a current density $>60 \mathrm{~mA} \mathrm{~cm}^{-2}$. Even at a lower current density of $40 \mathrm{~mA} \mathrm{~cm}{ }^{-2}$, the BP-ArF4 membrane still exhibited a very high $\mathrm{CE}$ of $98.6 \%$, as compared with $95.0 \%$ exhibited by Nafion 117 and $85.9 \%$ by Nafion 212. Notably, the CE of BP-ArF4 was even higher than that of BPN1 (96.2\%) at $40 \mathrm{~mA} \mathrm{~cm}$. The high CE of BP-ArF4 can also be reflected from the chargedischarge curves (Fig. S4, ESI $\dagger$ ). The discharge capacity of BPArF4 is almost identical to the charge capacity, indicating that the loss of the discharge capacity has been minimized.

Since the CE and EE values of the BP-ArF4, BP-ArSA, BPN1, and Nafion 212 are similar at $100 \mathrm{~mA} \mathrm{~cm}^{-2}$ (Fig. 2a and c), we monitored the capacity retention of the IEMs to further evaluate their performance, particularly at a high current density. VRFB single cells loaded with each IEM were charged and discharged at $100 \mathrm{~mA} \mathrm{~cm} \mathrm{~cm}^{-2}$ for 200 cycles. As shown in Fig. 2d, BP-ArF4 has the lowest capacity decay rate $(0.08 \%$ per cycle) followed by BP-ArSA (0.16\%), Nafion 117 (0.29\%), BPN1 (0.36\%), Nafion $212(0.44 \%)$, and BP-SA (0.49\%). The capacity decay of the VRFB cell is typically a result of the charge imbalance due to the crossover of vanadium ions as well as water transfer. ${ }^{34}$ Benefiting from remarkably lower vanadium permeability and swelling ratio, BP-ArF4 and BP-ArSA exhibited a slow capacity decay rate and maintained high capacity retention after 200 cycles, $84 \%$ and $67 \%$, respectively. In contrast, (a)

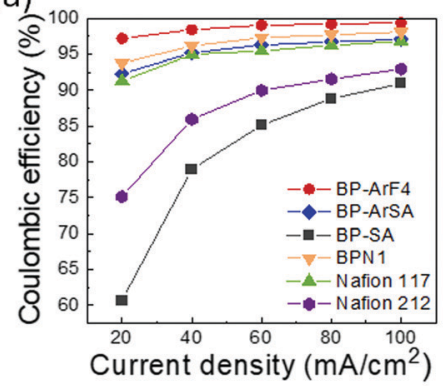

(d)

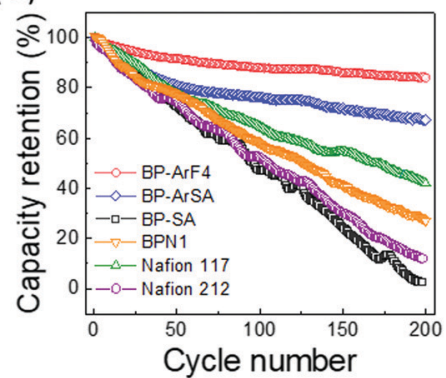

(b)

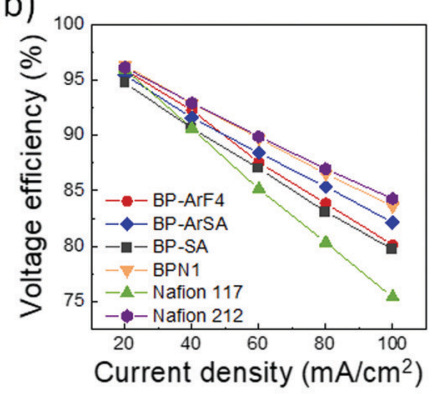

(e)

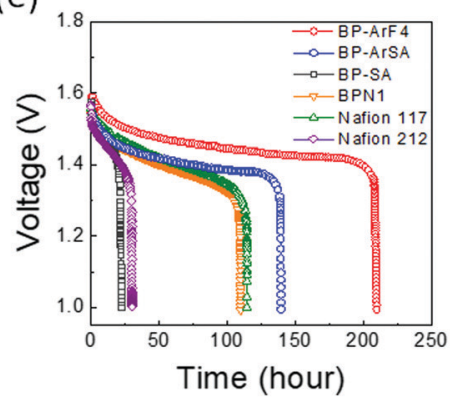

(c)

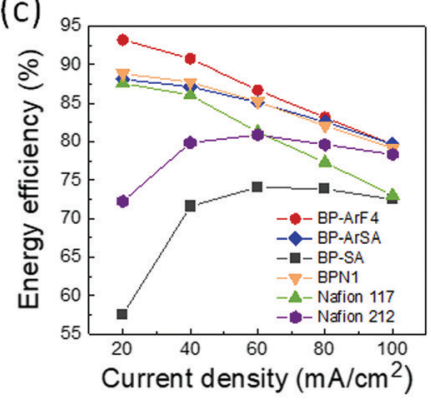

(f)

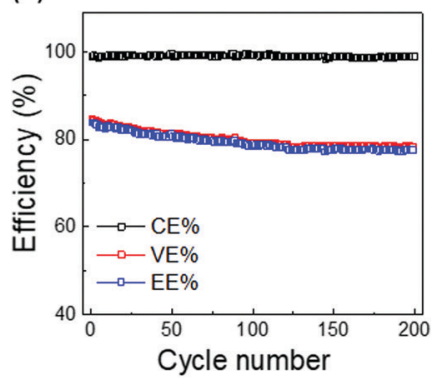

Fig. 2 VRFB single cell performance. (a) CE for PEMs at a current density from 20 to $100 \mathrm{~mA} \mathrm{~cm}^{-2}$, (b) VE for PEMs at a current density from 20 to $100 \mathrm{~mA} \mathrm{~cm}^{-2}$, (c) EE for PEMs at a current density from 20 to $100 \mathrm{~mA} \mathrm{~cm}^{-2}$, (d) capacity retention for IEMs at $100 \mathrm{~mA} \mathrm{~cm}^{-2}$, (e) self-discharge curves of PEMs, and (f) cycling stability of VRFB with the BP-ArF4 membrane at $100 \mathrm{~mA} \mathrm{~cm}^{-2}$. 
BP-SA showed a faster capacity decay and lower capacity retention, presumably due to the more rapid vanadium and water crossover, which can deteriorate the charge imbalance between positive and negative half cells. Nafion 117 was able to achieve a higher capacity retention than Nafion 212 (40\% vs. 10\% after 200 charge-discharge cycles) by lowering vanadium ion crossover with increased thickness. Additionally, we evaluated the self-discharge rate of the IEMs which is closely related to the loss of energy capacity of VRFB. ${ }^{35,36}$ Fig. 2e shows the selfdischarge curves of VRFB with IEMs starting from $\sim 90 \%$ of the state of charge (SOC). Since the cells were held statically (zero current) during the self-discharge test, the difference of overpotential between each membrane is minimized. Therefore, the initial open circuit voltage (OCV) for all membranes approaches 1.6 V. However, because of the different crossover rates of active vanadium species through membrane separators, the OCV of VRFB cells decreased over time at varying speed. Toward the end of the test, OCV sharply decreased below 1.0 V. When OCV tests were compared with $1.0 \mathrm{~V}$ as a cut-off voltage, BP-ArF4 exhibited the longest self-discharge time $(209.5 \mathrm{~h})$ among all tested IEMs: BP-ArSA (139.5 h), Nafion 117 (114.5 h), BPN1 (109.9 h), Nafion 212 (30.5 h), and BP-SA (22.2 h). Interestingly, the $90 \mu$ m-thick BP-ArF4 membrane showed almost twice longer self-discharging time than the $195 \mu \mathrm{m}$-thick Nafion 117, owing to its superior ability to mitigate vanadium crossover. Overall, the results of capacity retention and selfdischarge tests agree well with the trend of vanadium permeability results provided in Table 1 ; the lower the vanadium permeability of the membrane, the higher the capacity retention and the longer the self-discharge time in a VRFB single cell.

We also evaluated the cycling stability and chemical stability of BP-ArF4 in oxidative/acidic $\mathrm{V}^{5+} / \mathrm{H}_{2} \mathrm{SO}_{4}$ solution and compared with Nafion membranes. The high CE of BP-ArF4 remained stable (nearly constant close to 100\%) during the 200 charge-discharge cycles at $100 \mathrm{~mA} \mathrm{~cm}^{-2}$, which indicates negligible crossover of vanadium ions through the membrane during the operation and good chemical stability in the strong oxidizing acidic environment (Fig. 2f). The observed decrease of VE and EE during the first 100 cycles is most likely due to the electrochemical degradation of carbon electrodes, as encountered in other works. ${ }^{37,38}$ While EE of BP-ArF4 remained almost stable at $80 \%$ after 110 cycles and slightly decreased to $79 \%$ at 200 cycles, the EEs of VRFB cycling stability of the Nafion 212 and 117 membranes continuously decreased to $73 \%$ and $68 \%$ after 200 cycles, respectively (Fig. S5, ESI $\dagger$ ). When the chemical stability of the IEMs was evaluated in $0.1 \mathrm{M} \mathrm{V}^{5+}$ in $4 \mathrm{M} \mathrm{H}_{2} \mathrm{SO}_{4}$, all our biphenyl CEMs showed significantly lower $\mathrm{V}^{4+}$ generation than other hydrocarbon PEMs such as BPSH60 ${ }^{39}$ (Fig. S6, ESI $\dagger$ ). We believe that the enhanced chemical stability stems from the absence of chemically labile aryl ether bonds in the polymer backbone. As all biphenyl CEMs reported here have polymer backbones made only of carbon-carbon bonds, they should be chemically more resistant to strongly acidic oxidizing environments than aryl ether-containing polymer CEMs such as BPSH60. Among biphenyl CEMs, BP-SA which does not have any heteroatom other than $\mathrm{CF}_{3}-$ and $-\mathrm{SO}_{3} \mathrm{H}$ moieties in the chemical structure exhibited the greatest chemical resistance against oxidation. Notably, the chemical stability of BP-SA is almost comparable to that of perfluorinated polymer Nafion, which is unprecedented for a hydrocarbon-based CEM. Overall, both the battery cycling test and off-cell chemical stability test clearly suggest that our biphenyl CEMs are quite stable in VRFBs during long-term operation.

\section{SAXS and DFT studies: selective ion transport mechanism}

On the basis of our recent work on selective ion transport, ${ }^{40,41}$ we suggest that the exceptionally good battery performance of BP-ArF4 is due to its unique morphology created by the polymer structure of rigid biphenyl backbone and long tethered perfluoroalkylsulfonate side chain and optimum ion exchange capacity. When equilibrated with a $1.6 \mathrm{M} \mathrm{VOSO}_{4} / 4 \mathrm{M} \mathrm{H}_{2} \mathrm{SO}_{4}$ electrolyte, the hydration number (swelling) of the CEMs was low (Table 2) and a substantial amount of co-ions (sulfate/ bisulfate anions) entered the membrane with a corresponding amount of counter-ions (mostly $\mathrm{H}_{3} \mathrm{O}^{+}$and vanadyl species). Interestingly, there was a strong indication that $\mathrm{VO}^{2+}$ counterions were well hydrated and dissociated (they did not bind to the $-\mathrm{SO}_{3}{ }^{-}$fixed ionic group), whereas excess $\mathrm{VO}^{2+}$ was strongly associated with $\mathrm{SO}_{4}{ }^{2-}$ co-ions by forming neutral $\mathrm{VOSO}_{4}$ species within the aqueous domains of the CEMs. Then, vanadium crossover mainly occurred through $\mathrm{VOSO}_{4}$ diffusion, with a minor contribution from charged vanadium species, whereas the major contribution to the ionic current through the membrane was from protons, which were present as counterions and part of the excess $\mathrm{H}_{2} \mathrm{SO}_{4}$ entering the membrane as a consequence of the breakdown of Donnan exclusion at high acid concentrations (i.e., $4 \mathrm{M} \mathrm{H}_{2} \mathrm{SO}_{4}$ ). We also demonstrated that the transport of vanadium-containing species was largely decreased when the extension of aqueous domains fell below

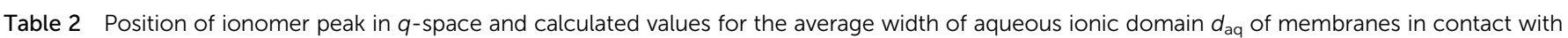

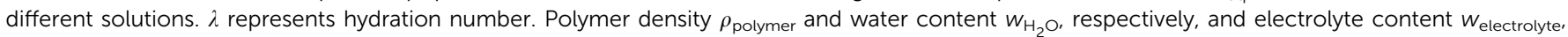
were used to calculate $d_{\mathrm{aq}}$ using eqn (1)

\begin{tabular}{|c|c|c|c|c|c|c|c|c|}
\hline \multirow[b]{2}{*}{ Samples } & \multirow{2}{*}{$\frac{\text { Density }}{\rho_{\text {polymer }}\left(\mathrm{g} \mathrm{cm}^{-3}\right)}$} & \multicolumn{4}{|c|}{$\mathrm{H}^{+}$form in water } & \multicolumn{3}{|c|}{$\underline{\text { In } 4 \mathrm{M} \mathrm{H}_{2} \mathrm{SO}_{4} / 1.6 \mathrm{M} \mathrm{VOSO}_{4}}$} \\
\hline & & $q\left(\AA^{-1}\right)$ & $w_{\mathrm{H}_{2} \mathrm{O}}(\%)$ & $\lambda$ & $d_{\mathrm{aq}}(\mathrm{nm})$ & $q\left(\AA^{-1}\right)$ & $w_{\text {electrolyte }}(\%)$ & $d_{\mathrm{aq}}(\mathrm{nm})$ \\
\hline Nafion 117 & 2.1 & 0.124 & 25 & 20.4 & 2.10 & 0.149 & 21 & 1.20 \\
\hline BP-ArF4 & 1.4 & 0.156 & 28 & 17.3 & 1.41 & 0.190 & 19 & 0.63 \\
\hline BP-ArSA & 1.2 & 0.162 & 32 & 13.0 & 1.41 & 0.210 & 28 & 0.75 \\
\hline BP-SA & 1.2 & 0.184 & 50 & 24.3 & 1.85 & 0.224 & 37 & 0.94 \\
\hline
\end{tabular}


the hydrated sizes of these species (sieving-effect), which was also observed in the subnano-sieving PIM-1 membrane. ${ }^{42}$ This effect began to occur at a domain width of approx. $0.7 \mathrm{~nm}$, which remained wide enough for rapid local $\mathrm{H}_{3} \mathrm{O}^{+}$diffusion.

With their pronounced hydrophobic/hydrophilic separation, as indicated in Table 2, perfluorosulfonic acid membranes, Nafion 117 and Nafion 212, have much wider aqueous domains, despite the lower swelling in highly concentrated electrolytes (i.e., 1.6 M VOSO $4 / 4 \mathrm{M} \mathrm{H}_{2} \mathrm{SO}_{4}$ ), thus explaining their low $\mathrm{CE}$ values. In contrast, the flexible and long side chains of Nafion efficiently decouple hydrophobic aggregation within the polymeric domain from ionic ordering and water coalescence within the aqueous ionic domain, thus leading to a relatively smooth interface between the two domains and good connectivity of the aqueous ionic domain. Consequently, even with low IEC, Nafion membranes show less of a conductivity decrease than other IEMs as hydration decreases. ${ }^{43}$ With respect to low hydration conditions, such as those in VRFBs, relatively high proton conductivity can still be achieved, thus leading to high VE for a given current density (Fig. 2b). Therefore, a key design criterion for obtaining both high CE and VE is the morphology of the IEMs, which should have narrow aqueous ionic domains that efficiently block the transport of vanadium species (e.g., $\mathrm{VOSO}_{4}, \mathrm{VO}_{\mathrm{aq}}{ }^{2+}, \mathrm{VO}_{\mathrm{aq} 2}{ }^{+}, \mathrm{V}_{\mathrm{aq}}{ }^{3+}, \mathrm{V}_{\mathrm{aq}}{ }^{2+}$ ) but are still wide enough and well-connected for high proton conductivity.

To investigate how the average width of the aqueous ionic domain $d_{\text {aq }}$ and the degree of order/disorder affect ion selectivity and VRFB performance, we recorded SAXS patterns for CEMs immersed in pure water and in $1.6 \mathrm{M} \mathrm{VOSO}_{4} / 4 \mathrm{M} \mathrm{H}_{2} \mathrm{SO}_{4}$ (Fig. 3). From the structural correlation length $d$ obtained from the position of the ionomer peak in $q$-space, $d_{\mathrm{aq}}$ is estimated by using eqn (1).

$$
d_{\mathrm{aq}}=d \frac{V_{\mathrm{aq}}}{\left(V_{\mathrm{aq}}+V_{\text {poly }}\right)},
$$

where $V_{\text {aq }}$ and $V_{\text {poly }}$ are the volume fractions of the aqueous ionic domain and the polymeric domain, respectively.

This estimation is based on the assumption that the structural correlation length $d$ of the present ionomers scales in a linear fashion with the volume fraction of the aqueous ionic domain $V_{\text {aq }}$ as observed for other CEMs with sulfonic-acid as fixed ionic groups. ${ }^{44}$ This corresponds to the local anisotropic swelling, which had been claimed to be characteristic for the locally flat morphologies with the dominant swelling component parallel to the normal. ${ }^{44}$

The relevant data are shown in Table 2. BP-ArF4 has the unique molecular structure of a hydrocarbon backbone and flexible pendant side chains with a perfluorinated terminating part (Fig. 1a). Although the BP-ArF4 membrane does not show the smallest structural correlation length $d$, its $d_{\mathrm{aq}}$ is the smallest as compared with other membranes, owing to its lower water volume fraction, essentially reflecting the low IEC. Notably, the ionomer peak of BP-ArF4 is relatively narrow, and the second order peak is clearly visible (Fig. $3 \mathrm{~b}$ and c), thus indicating a well-ordered morphology with a narrow distribution of the aqueous ionic domain width. This finding may be a reason for its superior blocking properties for vanadium species, thus leading to the highest CE over the entire current densities (20-100 $\mathrm{mA} \mathrm{cm}^{-2}$ ). Despite low IEC, BP-ArF4 maintains good ion conductivity because of the super-acidic perfluorosulfonate group which leads to its reasonably high VE.
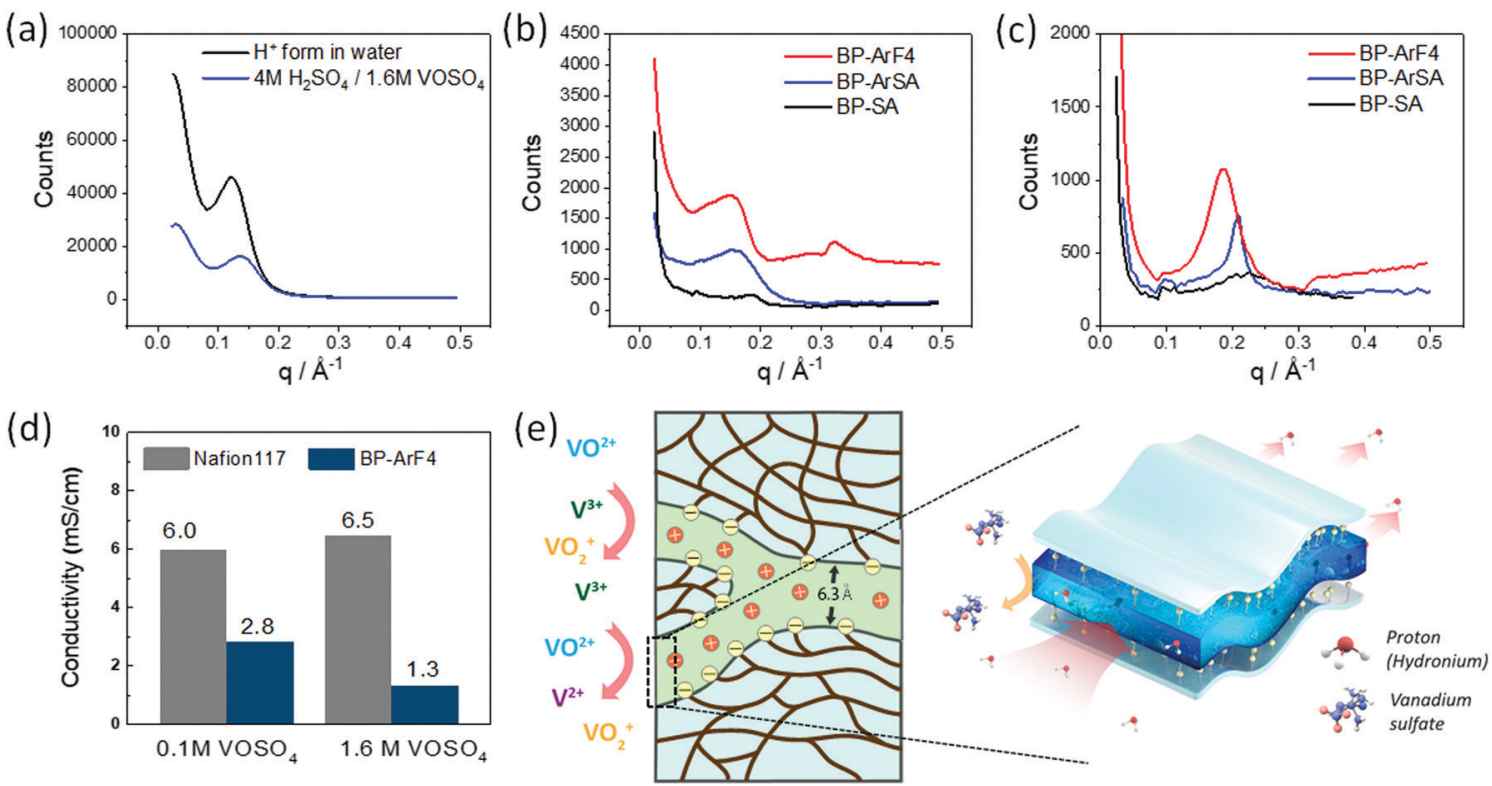

Fig. 3 SAXS patterns of: (a) Nafion 117 in water and $4 \mathrm{M} \mathrm{H}_{2} \mathrm{SO}_{4} / 1.6 \mathrm{M} \mathrm{VOSO}_{4}$, (b) BP-ArF4, BP-ArSA, and BP-SA membranes in the acid-form immersed in water, and (c) equilibrated in $1.6 \mathrm{M} \mathrm{VO}_{2} \mathrm{SO}_{4} / 4 \mathrm{M} \mathrm{H}_{2} \mathrm{SO}_{4}$ electrolyte. (d) Total room temperature conductivity of Nafion 117 and BP-ArF4 membranes equilibrated in solutions of $\mathrm{VOSO}_{4}$ with different molarities. (e) Illustration of the selective ion transport mechanism of BP-ArF4 membrane. The narrow aqueous ionic channel $(0.63 \mathrm{~nm})$ and functionalities of BP-ArF4 can efficiently block $\mathrm{VOSO}_{4}$ transport, while keeping high proton conductivity. 
These characteristics of CE and VE lead to a better compromise than for other types of membranes. Therefore, the results of SAXS studies indicate that the unique molecular structure of BP-ArF4 with narrow aqueous ionic domains can afford the combination of properly sized aqueous ionic transport pathways and the high degree of order. The morphological "sieving" effect can be characterized by a relatively distinct threshold with respect to the width of the aqueous ionic domain. ${ }^{43}$ It is the very nature of this effect that only a narrow distribution of this width allows for a high blocking effect close to the percolation threshold. Otherwise, one has to further reduce the average width of the transport pathways so as to avoid transport through the fraction of wider parallel pathways. This would further reduce proton conductivity which is also the highest for a narrow domain width distribution because of the non-linear dependence of the water diffusion coefficient on the water volume fraction (domain width). ${ }^{43}$ As shown in Fig. $3 \mathrm{~b}$ and c, the morphology of the BP-ArF4 membrane could provide both properly sized aqueous ionic domains and a high degree of order. The molecular structure of this ionomer represents a rare case of a hydrocarbon backbone with flexible pendant side chains with a perfluorosulfonate terminating group (see chemical structure of BP-ArF4 in Fig. 1). This allows for the formation of a well-developed ordered hydrophobic/hydrophilic separation, while hydrocarbon structures with sulfonic groups tethered to the main chain via a short chain, such as BP-SA, are by far less ordered on the nano-meter scale as indicated by broad ionomer peaks of the SAXs patterns (Fig. 3b and c). It should also be mentioned that the superacidity of the terminating group of BP-ArF4 guarantees quasi complete dissociation at reduced water activity characteristics for VRFB electrolytes.

We further investigated the transport phenomena of vanadium species in two extreme cases, Nafion 117 (the largest $d_{\mathrm{aq}}$ ) and BP-ArF4 (the smallest $d_{\mathrm{aq}}$ ), by estimating $\mathrm{VOSO}_{4}$ transport rates. Because both membranes enabled complete exchange into $\mathrm{VO}^{2+}$ form in an excess of $0.1 \mathrm{M} \mathrm{VOSO}_{4}$ with limited uptake of excess $\mathrm{VOSO}_{4}(<10 \%$ of the fixed ion concentration), the total conductivity mainly represented the mobility of $\mathrm{VO}_{\mathrm{aq}}{ }^{2+}$ in both structures (the volumetric density of ionic groups in both membranes was very close, i.e., approximately 1.9 meq. $\mathrm{mL}^{-1}$ ). As shown in Fig. 3d, the total conductivity of BP-ArF4 $\left(2.8 \mathrm{mS} \mathrm{cm}{ }^{-1}\right)$ is lower than that of Nafion $117\left(6 \mathrm{mS} \mathrm{cm}^{-1}\right)$ by approximately a factor of two. A more interesting observation was that the increase in the $\mathrm{VOSO}_{4}$ concentration from 0.1 to $1.6 \mathrm{M}$ left the total conductivity of Nafion 117 unchanged while the value of BP-ArF4 largely decreased to $1.3 \mathrm{mS} \mathrm{cm}^{-1}$. In the highly concentrated electrolytes, we observed a substantial amount of co-ion $\left(\mathrm{SO}_{4}{ }^{2-}\right)$ uptake, mainly from neutral $\mathrm{VOSO}_{4}$ and diminished water uptake (approximately 10\%) as a response to the decreased water activity in the electrolyte solution. Thus, in more highly concentrated electrolytes with a further decrease in the membrane's hydration, the conductivity contribution of vanadium species $\left(\right.$ e.g., $\left.\mathrm{VO}^{2+}\right)$ can be further decreased in the BP-ArF4 after its de-swelling. The lower swelling can decrease the width of the aqueous ionic domain to an extent (e.g., $0.63 \mathrm{~nm}$ in Table 2 ), which substantially impedes vanadium ions, whereas protons still can be transported through the channels. This result is consistent with the recent molecular dynamics simulation study which suggests that zeolite-based IEMs with pore size $<0.7 \mathrm{~nm}$ are crucial for the selective hydronium ion transport over vanadium ions. ${ }^{45}$

DFT calculation results provided additional insights into vanadium ion transport in terms of the chemical functionalities of polymer chains. A previous study has reported that the vanadium(Iv) ion in sulfuric acid solution forms a $\left[\mathrm{VO}\left(\mathrm{SO}_{4}\right)\left(\mathrm{H}_{2} \mathrm{O}\right)_{4}\right] \mathrm{H}_{2} \mathrm{O}$ complex. ${ }^{46}$ Our further optimized vanadium ion structures indicated that the energetics of the vanadium ion was the lowest when its spin state was a doublet (Fig. S7, ESI $\dagger$ ), and its structural parameters, such as the $\mathrm{V}=\mathrm{O}$ bond length and $\mathrm{V}-\mathrm{O}$ bond length, were in good agreement with previously reported values. ${ }^{47}$ Fig. S8-S11 (ESI $\dagger$ ) illustrate the optimized structures of the vanadium ion complexes with different moieties of the sulfonated aromatic IEMs including Nafion and Table S1 (ESI $\dagger$ ) lists the interaction energies (detailed calculation methods and optimized structures of IEMs can be found in the ESI $\dagger$ ). The interaction energies between BP-ArF4 and vanadium ion were in the range of 22.6-33.8 $\mathrm{kcal} \mathrm{mol}^{-1}$, which are significantly higher than those of other IEMs (14.2-21.4 kcal mol$\left.{ }^{-1}\right)$. The higher interaction energy is due to the strong binding energy through $\pi \cdots \mathrm{H}$ and $\pi \cdots \mathrm{F}$ hydrogen bonding in BP-ArF4 and vanadium ion complexes (Fig. S7, ESI $\dagger$ ), which hinders the diffusion of vanadium ions through the polymer membrane. Among several complexes, comp3-BP-ArF4, the optimized structure of which is depicted in Fig. S8c (ESI $\dagger$ ), showed a remarkably large binding energy (33.8 $\left.\mathrm{kcal} \mathrm{mol}^{-1}\right)$. In this complex, three hydrogen atoms of the vanadium ion interact with the fluorine atoms of BP-ArF4, which should contribute to the interaction to a large extent. In addition, the fourth hydrogen atom $\left(\mathrm{H}_{\mathrm{D}}\right)$ interacts with the neighboring aromatic moiety. The formation of three $\pi \cdots$ F hydrogen bonding between vanadium ions and BP-ArF4 is possible because of the uniquely designed side chain structure of BP-ArF4 in which the flexible $-\mathrm{CF}_{2} \mathrm{CF}_{2} \mathrm{OCF}_{2} \mathrm{CF}_{2} \mathrm{SO}_{3} \mathrm{H}$ side chain is attached to the neighboring aromatic ring. In contrast, the interaction of Nafion with vanadium complexes occurs around its fluorine atoms, owing to the absence of an aromatic ring in the backbone or side chains (Fig. S11, ESI $\dagger$ ). All complexes of Nafion showed that two hydrogen atoms of the vanadium complex interact with the $-\mathrm{CF}_{3}$ group of Nafion. Thus, the computed binding energies indicated that the interaction between Nafion and the vanadium complex is weaker (13.7 and $21.0 \mathrm{kcal} \mathrm{mol}^{-1}$ for complexes with comp1 and comp2, respectively) than that of BP-ArF4 (Table S1, ESI $\dagger$ ). Although the fluorine atoms in the $-\mathrm{CF}_{3}$ group typically have a sizeable negative charge, their hydrogen bonding ability with hydrogen donor molecules is rather weak. ${ }^{48}$

As graphically illustrated in Fig. 3e, the extraordinary high ion selectivity property and VRFB performance of BP-ArF4 are believed to be derived from the synergistic effects of its unique morphology and functionalities in the polymer chain which greatly hinder the vanadium ion transport, while keeping high 
proton conductivity. We also investigated the differences of VOSO $_{4}$ transport in BP-ArF4 and Nafion 117 by comparing the permeation activation energies. The activation energies of $\mathrm{VOSO}_{4}$ transport for BP-ArF4 and Nafion 117 membranes were calculated using Arrhenius plots obtained by measuring the $\mathrm{VOSO}_{4}$ permeability at different temperatures. As shown in Table S2 (ESI $\dagger$ ), BP-ArF4 has almost two times higher activation energy (9.14 kcal mol$\left.{ }^{-1}, 0.40 \mathrm{eV}\right)$ than Nafion 117 (4.5 $\mathrm{kcal} \mathrm{mol}^{-1}$, $0.20 \mathrm{eV}$ ) and Nafion $212\left(5.4 \mathrm{kcal} \mathrm{mol}^{-1}, 0.23 \mathrm{eV}\right)$, which agrees with the conclusion from our simulation data provided in Table S1 (ESI $\dagger$ ) and the conductivity measurement from $\mathrm{VOSO}_{4}$ equilibrated solutions shown in Fig. 3c.

\section{Breaking the trade-off limitations in IEMs}

Finally, to evaluate the battery performance with the ion transport properties of BP-ArF4, we compared its trade-off of ion selectivity and membrane resistivity with other highperformance CEMs and AEMs reported to date (Fig. 4). To make a fair comparison, the performance of IEMs that were enhanced with additional components or by thickness optimization (e.g., mixed matrix membranes, blended membranes, and nanocomposite membranes) are not included in the figure. As all data of BP-ArF4 in this report were obtained from membranes in the form of a free-standing film directly related to the polymer's unique properties, they should be compared with the performance of membranes made of a single polymer. For example, low areal resistance $\left(3.9 \times 10^{-2} \Omega \mathrm{cm}^{2}\right)$ and high ion conductivity $\left(0.27 \mathrm{~S} \mathrm{~cm}^{-1}\right)$ values of a recently reported polyamide thin-film composite membrane were obtained by normalizing the resistance and conductance with the entire thickness of the composite membrane (support layer + polyamide selective layer) rather than using a thin selective polyamide layer. ${ }^{49}$ Considering that the intrinsic resistivity and ion conductivity of the polyamide layer are $\sim 706 \Omega \mathrm{cm}^{2}$ and $1.4 \times$ $10^{-3} \mathrm{~S} \mathrm{~cm}^{-1}$, respectively, a trade-off comparison between BP-ArF4 and thin-film composite membranes does not provide insightful information about the properties of the materials.

As shown in Fig. 4a, BP-ArF4 has the best combination of low membrane resistivity and low vanadium permeability outperforming all CEM and AEM materials reported so far. Generally, CEMs show low resistivity and high vanadium permeability, while AEMs
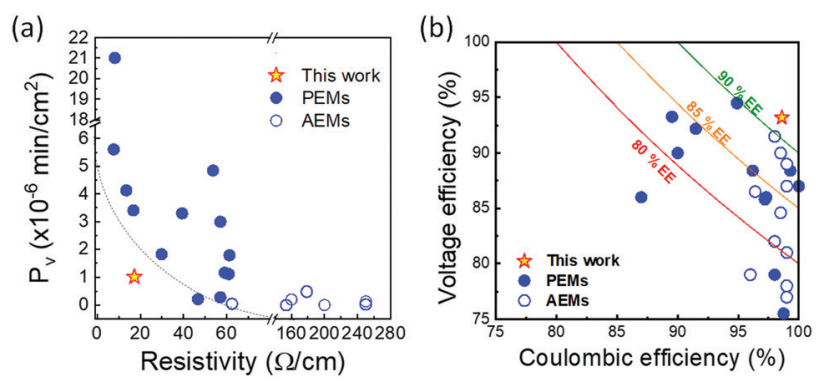

Fig. 4 (a) Trade-off between vanadium diffusivity and resistivity. (b) VRFB performance relationship among CE, VE, and EE at 40-60 $\mathrm{mA} \mathrm{cm}^{-2}$. Detailed information on the trade-off curves is available in Tables S3 and S4 (ESI $\dagger)$. show high resistivity and low vanadium permeability. Notably, the performance of BP-ArF4 overcomes the conventional trade-off limitation of ion selectivity and resistivity of IEMs. The high proton selectivity over vanadium ions by BP-ArF4 demonstrates its great potential for application in VRFBs. Indeed, Fig. 4b shows a tradeoff relationship between $\mathrm{CE}$ and $\mathrm{VE}$, which is similar to the ion selectivity/conductivity trade-off. With a few exceptions, IEMs with high VE tend to show low CE due to high crossover of vanadium species and vice versa. However, BP-ArF4 illustrates a remarkable combination of high $\mathrm{CE}$ with high $\mathrm{VE}$, resulting in one of the highest EEs reported in the literature. It outperforms most of the CEMs and AEMs for VRFB systems reported to date and mitigates the trade-off limitation on battery performance due to the highly selective proton/vanadium ion transport.

\section{Conclusions}

In summary, we developed a novel class of sulfonated aromatic polymers that have a good combination of high proton conductivity and ion selectivity, and can greatly mitigate the tradeoff limitations of conventional IEMs. The effects of the pendant group structure of the polymer on the IEM's ion selectivity and battery performance were investigated. The incorporation of an aromatic ring and a short perfluoroalkyl chain on the pendant group of BP-ArF4 greatly improved the proton/vanadium ion selectivity, which is three times higher than that of Nafion ${ }^{\mathbb{R}}$, the standard CEM in VRFB. With excellent vanadium ion blocking capacity and good proton conductivity, BP-ArF4 achieved high CE and VE values in a VRFB single cell. SAXS and DFT calculation studies revealed that the narrowly distributed aqueous ionic domain width of BP-ArF4 and the strong interaction between the side chain of the polymer and vanadium ion complexes through $\pi \cdots \mathrm{H}$ or $\pi \cdots \mathrm{F}$ hydrogen bonding synergistically improve proton/vanadium ion selectivity. This study suggests an effective path toward the design of highperformance IEMs that can overcome the trade-off limit of ion selectivity/conductivity in other energy conversion and storage systems. Enhanced evaluations on the IEM performance in VRFB (e.g. longer cyclic stability test, volumetric imbalance measurement) will further validate their practical-level cycling stability and efficiency. Additional optimization, such as nanocomposite membranes, using the unique material platform of BP-ArF4 as a base material can lead to more advanced IEMs with further improvement in efficiencies of energy storage systems.

\section{Experimental section}

\section{Reagents}

The biphenyl precursor polymer BPBr-100 $\left(M_{\mathrm{n}}=60 \mathrm{~kg} \mathrm{~mol}^{-1}\right.$, $M_{\mathrm{w}} / M_{\mathrm{n}}=2.0$ ) was synthesized using an acid-catalyzed polycondensation method as mentioned in our previous reports. ${ }^{28,50}$ Potassium thioacetate (Sigma-Aldrich, 98\%), formic acid (VWR, $88 \%$ ), hydrogen peroxide aqueous solution (ACROS, $35 \mathrm{wt} \%$ ), sodium 4-hydroxybenzenesulfonate (TCI, >98\%), 4-iodophenol 
(Sigma-Aldrich, 99\%), tetrafluoro-2-(tetrafluoro-2-iodoethoxy) ethanesulfonyl fluoride (Sigma-Aldrich, 97\%), and copper powder (Sigma-Aldrich, 99\%, 200 mesh) were used as received without further purification. Sodium hydroxide, potassium hydroxide and potassium carbonate (anhydrous) were purchased from Fisher Scientific. Ethanol, methanol, tetrahydrofuran (THF), dimethyl sulfoxide (DMSO) and $N, N$-dimethylacetamide (DMAc) were of reagent grade and used without further purification. Commercial Nafion ${ }^{\circledR} 117$ and 212 membranes were purchased from Ion Power Inc. (DE, USA). Vanadyl sulfate $\left(\mathrm{VOSO}_{4}, 99.9 \%\right)$ and magnesium sulfate $\left(\mathrm{MgSO}_{4}, 99.5 \%\right)$ were purchased from Alfa Aesar (MA, USA). Sulfuric acid $\left(\mathrm{H}_{2} \mathrm{SO}_{4}, 98.0 \%\right)$ was purchased from Fisher Scientific (PA, USA).

\section{Polymer synthesis and characterization}

\section{BP-SA}

Synthesis of BP-TA. BPBr-100 (5.00 g, $13.0 \mathrm{mmol})$, potassium thioacetate $(5.19 \mathrm{~g}, 45.4 \mathrm{mmol})$ and THF $(150 \mathrm{~mL})$ were added to a $250 \mathrm{~mL}$ round-bottom flask. After the precursor polymer was fully dissolved, the reaction flask was connected to a reflux condenser and was heated to $50{ }^{\circ} \mathrm{C}$ for $12 \mathrm{~h}$. After cooling to room temperature, methanol $(450 \mathrm{~mL})$ was added to the solution to precipitate the polymer, which was then collected by vacuum filtration and dried. The crude polymer product was dissolved in THF ( $95 \mathrm{~mL}$ ) and filtered through a cotton plug to remove insoluble solids. The filtrate was poured into methanol to precipitate BP-TA which was collected by filtration and dried under vacuum at $80{ }^{\circ} \mathrm{C}$ for $15 \mathrm{~h}$ (yield: $\left.4.86 \mathrm{~g}\right) .{ }^{1} \mathrm{H} \mathrm{NMR}\left(\mathrm{CDCl}_{3}\right)$ : $\delta(\mathrm{ppm})=7.57(\mathrm{~d}, 4 \mathrm{H}), 7.36(\mathrm{~d}, 4 \mathrm{H}), 2.8(\mathrm{t}, 2 \mathrm{H}), 2.43(\mathrm{~m}, 2 \mathrm{H})$, $1.52(\mathrm{~m}, 2 \mathrm{H}), 1.37(\mathrm{~m}, 2 \mathrm{H}), 1.24(\mathrm{~m}, 2 \mathrm{H})$.

Fabrication of BP-SA membrane. Once BP-TA was converted to the sulfonic acid form in BP-SA, it exhibited poor solubility in all organic solvents. Thus, the oxidation of the thioacetate group of BP-TA to the $-\mathrm{SO}_{3} \mathrm{H}$ of BP-SA was conducted in a membrane form after casting BP-TA film from a $5 \mathrm{wt} \%$ THF solution onto a glass plate. After the membrane was dried, the oxidation was performed with a mixture of $6 \mathrm{M}$ formic acid and hydrogen peroxide aqueous solution (35 wt\%) in a glass container at $50{ }^{\circ} \mathrm{C}$ for $3 \mathrm{~h}$. The membrane was then removed from the container and washed extensively with water.

\section{BP-ArSA}

Synthesis of BP-ArSA. BPBr-100 (3.00 g, $7.80 \mathrm{mmol})$, sodium 4-hydroxybenzenesulfonate $(5.00 \mathrm{~g}, 25.5 \mathrm{mmol})$, and potassium hydroxide $(1.80 \mathrm{~g}, 32.0 \mathrm{mmol})$ were added to a $250 \mathrm{~mL}$ roundbottom flask. Anhydrous DMSO (75 mL) and THF $(15 \mathrm{~mL})$ were added into the flask; then the reaction mixture was stirred at $40{ }^{\circ} \mathrm{C}$ for $24 \mathrm{~h}$ after which THF was removed under reduced pressure. The concentrated polymer in DMSO solution was stirred for an additional $12 \mathrm{~h}$. After cooling to room temperature, the solution was poured into acetone $(450 \mathrm{~mL})$ to precipitate the polymer, which was washed with methanol to remove excess sodium 4-hydroxybenzenesulfonate. The polymer product was filtered and dried under vacuum at $50{ }^{\circ} \mathrm{C}$ for $12 \mathrm{~h}$ before fabricating into membrane (yield: $3.8 \mathrm{~g}$ ). ${ }^{1} \mathrm{H}$ NMR $\left(\right.$ DMSO- $\left.d_{6}\right): \delta(\mathrm{ppm})=7.75(\mathrm{~d}, 4 \mathrm{H}), 7.48(\mathrm{~d}, 2 \mathrm{H}), 7.37(\mathrm{~d}, 4 \mathrm{H})$, $6.79(\mathrm{~d}, 2 \mathrm{H}), 3.87(\mathrm{t}, 2 \mathrm{H}), 2.53(\mathrm{~m}, 2 \mathrm{H}), 1.63(\mathrm{~m}, 2 \mathrm{H}), 1.44$ $(\mathrm{m}, 2 \mathrm{H}), 1.20(\mathrm{~m}, 2 \mathrm{H})$.

\section{BP-ArF4}

Synthesis of BP-Ar-I. BPBr-100 (10.0 g, $26.2 \mathrm{mmol})$, 4iodophenol (17.75 g, $80.6 \mathrm{mmol})$, and potassium carbonate $(11.15 \mathrm{~g}, 80.6 \mathrm{mmol})$ were added to a $500 \mathrm{~mL}$ round-bottom flask which was connected with a reflux condenser under a positive flow of nitrogen. Anhydrous DMAc $(200 \mathrm{~mL})$ was added to the flask and the reaction mixture was stirred at room temperature until all reagents were completely dissolved and then heated to $90{ }^{\circ} \mathrm{C}$ for $3 \mathrm{~h}$. After cooling to room temperature, the solution was poured into methanol containing $\mathrm{HCl}(12 \mathrm{~mL})$ to precipitate the polymer. The collected polymer was re-dissolved in THF $(220 \mathrm{~mL})$, filtered through a cotton plug, and precipitated by dropping into methanol. Precipitated polymer was filtered and dried in a vacuum oven at $50{ }^{\circ} \mathrm{C}$ overnight to afford BP-ArI (yield: $13.5 \mathrm{~g}) .{ }^{1} \mathrm{H}$ NMR (DMSO- $\left.d_{6}\right): \delta(\mathrm{ppm})=$ $7.57(\mathrm{~d}, 4 \mathrm{H}), 7.49(\mathrm{~d}, 2 \mathrm{H}), 7.39(\mathrm{~d}, 4 \mathrm{H}), 6.60(\mathrm{~d}, 2 \mathrm{H}), 3.82(\mathrm{t}, 2 \mathrm{H})$, 2.47 (m, 2H), 1.71 (m, 2H), 1.47 (m, 2H), 1.31 (m, 2H).

Synthesis of sodium tetrafluoro-2-(tetrafluoro-2-iodoethoxy)ethanesulfonate (1). Tetrafluoro-2-(tetrafluoro-2-iodoethoxy)ethanesulfonyl fluoride $(5.00 \mathrm{~g}, 11.7 \mathrm{mmol})$ and $\mathrm{NaOH}$ solution ( $0.95 \mathrm{~g}$ in $6.5 \mathrm{~mL} \mathrm{H}_{2} \mathrm{O} ; 12.8 \mathrm{wt} \%$ ) were added to a $25 \mathrm{~mL}$ roundbottom flask connected with a reflux condenser, and then the reaction mixture was heated to $95{ }^{\circ} \mathrm{C}$ for $16 \mathrm{~h}$ in an oil bath. After the reaction completed, water was removed under vacuum at $60{ }^{\circ} \mathrm{C}$. Ethanol $(20 \mathrm{~mL})$ was added to the concentrated reaction mixture to precipitate sodium fluoride, which was removed by filtration through a cotton plug to give a clear solution. Removal of ethanol using a rotary evaporator gave compound 1 in sodium sulfonate form as an off-white powder which was dried in a vacuum oven at $50{ }^{\circ} \mathrm{C}$ overnight (yield: $5.20 \mathrm{~g}, 99.3 \%) .{ }^{19} \mathrm{~F}$ NMR $\left(\mathrm{D}_{2} \mathrm{O}\right): \delta(\mathrm{ppm})=-68.38(\mathrm{t}, 2 \mathrm{~F}),-83.17$ $(\mathrm{t}, 2 \mathrm{~F}),-86.31(\mathrm{t}, 2 \mathrm{~F}),-118.46(\mathrm{t}, 2 \mathrm{~F})$.

Synthesis of BP-ArF4. BP-Ar-I (3.05 g, $5.75 \mathrm{mmol}), \mathrm{Cu}(3.65 \mathrm{~g}$, $57.0 \mathrm{mmol})$, and DMAc $(18 \mathrm{~mL})$ were added to a $100 \mathrm{~mL}$ 2-neck round-bottom flask under a positive flow of nitrogen. After BP-Ar-I was dissolved, the reaction mixture was stirred at $95{ }^{\circ} \mathrm{C}$ for $1 \mathrm{~h}$. DMAc $(8.0 \mathrm{~mL})$ solution containing compound 1 (5.13 g, $11.5 \mathrm{mmol}$ ) was then added dropwise slowly via a syringe at $95{ }^{\circ} \mathrm{C}$. The reaction mixture was stirred at $95{ }^{\circ} \mathrm{C}$ for $2 \mathrm{~h}$, then at $120{ }^{\circ} \mathrm{C}$ for $48 \mathrm{~h}$ and then at $160{ }^{\circ} \mathrm{C}$ for $24 \mathrm{~h} .{ }^{51}$ The reaction mixture was cooled to room temperature and additional DMAc $(20 \mathrm{~mL})$ was added to dilute the polymer solution which was centrifuged at $9000 \mathrm{rpm}$ for $30 \mathrm{~min}$ to separate copper powder. The centrifuged polymer solution was filtered through a short silica plug to remove any fine copper residue and poured into Petri-dishes evenly to cast polymer films. The BP-ArF4 membranes (in $-\mathrm{SO}_{3} \mathrm{Na}$ form) were dried in a vacuum oven at $80{ }^{\circ} \mathrm{C}$, washed with warm water, and finally dried under vacuum (yield: $4.07 \mathrm{~g}) .{ }^{1} \mathrm{H}$ NMR (DMSO- $\left.d_{6}\right): \delta(\mathrm{ppm})=7.71(\mathrm{~d}, 4 \mathrm{H})$, $7.52(\mathrm{~d}, 2 \mathrm{H}), 7.37$ (d, 4H), $7.01(\mathrm{~d}, 2 \mathrm{H}), 3.94(\mathrm{t}, 2 \mathrm{H}), 2.52(\mathrm{~m}, 2 \mathrm{H})$, $1.66(\mathrm{~m}, 2 \mathrm{H}), 1.45(\mathrm{~m}, 2 \mathrm{H}), 1.21(\mathrm{~m}, 2 \mathrm{H}) .{ }^{19} \mathrm{~F}$ NMR (DMSO- $\left.d_{6}\right)$ : 
$\delta(\mathrm{ppm})-64.57\left(\mathrm{~s}, 3 \mathrm{~F},-\mathrm{CF}_{3}\right),-82.25(\mathrm{t}, 2 \mathrm{~F}),-87.08(\mathrm{t}, 2 \mathrm{~F})$, $-111.82(\mathrm{t}, 2 \mathrm{~F}),-117.92(\mathrm{t}, 2 \mathrm{~F})$.

\section{BPN1}

Synthesis of BPN1. BPN1 was prepared using a modified procedure mentioned in our previous report. ${ }^{50} \mathrm{BPBr}-100$ $(5.00 \mathrm{~g}, 13.0 \mathrm{mmol})$ was dissolved with DMAc $(50 \mathrm{~mL})$ in a $250 \mathrm{~mL}$ round-bottom flask. TMA in ethanol solution (33 wt\%, $20 \mathrm{~mL}$ ) was added to the flask and the reaction mixture was stirred at room temperature for $24 \mathrm{~h}$. The polymer was pre-

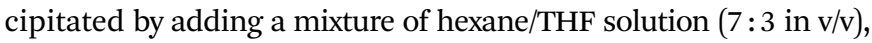
which was collected by filtration and dried under vacuum at $40{ }^{\circ} \mathrm{C}$ overnight. ${ }^{1} \mathrm{H}$ NMR (DMSO- $\left.d_{6}\right): \delta(\mathrm{ppm})=7.56(\mathrm{~d}, 4 \mathrm{H}), 7.39(\mathrm{~d}, 4 \mathrm{H})$, $3.22(\mathrm{t}, 2 \mathrm{H}), 3.01\left(\mathrm{~s},-\mathrm{CH}_{3}, 9 \mathrm{H}\right) 2.54(\mathrm{~m}, 2 \mathrm{H}), 1.61(\mathrm{~m}, 2 \mathrm{H}), 1.28$ $(\mathrm{m}, 2 \mathrm{H}), 1.20(\mathrm{~m}, 2 \mathrm{H})$.

Polymer molecular structure characterization. ${ }^{1} \mathrm{H}$ NMR spectra were obtained using a Varian Unity $500 \mathrm{MHz}$ spectrometer, and chemical shifts were referenced to the NMR solvent peaks; $\mathrm{CDCl}_{3}$ (at $7.26 \mathrm{ppm}$ ) and DMSO- $d_{6}$ (at $2.48 \mathrm{ppm}$ ). FT-IR spectra were obtained for the investigation of the functional groups of the synthesized polymer using a Thermo Nicolet Nexus 4700 FT-IR Spectrometer with ATR tool. The average molecular weight of the precursor polymer (BPBr-100) was determined using gel permeation chromatography (GPC, Viscotek T60A instrument), with THF as the eluent and a polystyrene standard curve.

\section{Membrane fabrication and characterization}

Membrane fabrication. Polymer solutions ( $c$. $5 \mathrm{wt} \%$ ) of different polymer/solvent pairs [BP-TA/THF, BP-ArSA/DMSO and BP-ArF4/DMAc (both ionic polymers in $-\mathrm{SO}_{3} \mathrm{Na}$ form), and BPN1/DMSO] were prepared to fabricate membranes with a thickness of 60-100 $\mu \mathrm{m}$. The thickness of the membrane was controlled to optimize their VRFB performance. Each polymer solution was cast on a glass plate and dried in a vacuum oven at $80{ }^{\circ} \mathrm{C}$ for $24 \mathrm{~h}$. The BP-SA membrane was obtained by the oxidation reaction of the BP-TA membrane as described in the synthetic procedure mentioned above. Fabricated membranes of BP-SA, BP-ArSA, and BP-ArF4 were placed in a $1 \mathrm{M} \mathrm{H}_{2} \mathrm{SO}_{4}$ solution at $80{ }^{\circ} \mathrm{C}$ for $2 \mathrm{~h}$ and then washed with water several times over a period of $24 \mathrm{~h}$. The BPN1 membrane with $\mathrm{Br}^{-}$ counter ion form was immersed in $1 \mathrm{M} \mathrm{Na}_{2} \mathrm{SO}_{4}$ solution for 24 hour and then washed three times with deionized water. The thicknesses of BP-ArSA, BP-ArF4, and BPN1 were in the range of $87-100 \mu \mathrm{m}$. The thickness of BP-SA $(60 \mu \mathrm{m})$ was thinner than that of the other BP-based membranes due to the different fabrication method (required oxidation).

Ion exchange capacity, water uptake, and swelling ratio. Weight-based ion exchange capacity (IECw) of the polymer membranes was calculated from the following titration method. Membranes were equilibrated in $1 \mathrm{M} \mathrm{NaCl}$ solution at room temperature for $24 \mathrm{~h}$, and then the solution was titrated with $0.01 \mathrm{M} \mathrm{NaOH}$ solution using phenolphthalein as the indicator. The IECw value was calculated from eqn (2):

$$
\mathrm{IEC}_{\mathrm{w}}=\frac{0.01 \times V_{\mathrm{NaOH}}}{W_{\mathrm{dry}}},
$$

where $V_{\mathrm{NaOH}}$ is the volume of $\mathrm{NaOH}$ solution added in titration, and $W_{\text {dry }}$ is the weight of membrane in a dry state.

Linear swelling (\%) was obtained by measuring the $x-y$ and diagonal length of dry and wet membrane samples. Water uptake $\left(W_{\mathrm{H}_{2} \mathrm{O}}\right.$ in wt\%) was measured by comparing the weights of wet $v s$. dry membranes at room temperature according to:

$$
W_{\mathrm{H}_{2} \mathrm{O}}=\frac{W_{\text {wet }}-W_{\text {dry }}}{W_{\text {dry }}} \times 100 \%,
$$

Hydration number $(\lambda)$, which is defined as molar ratio of water molecules per mole of ion exchange site, was obtained using the following calculation:

$$
\lambda=\frac{W_{\mathrm{H}_{2} \mathrm{O}}}{M_{\mathrm{H}_{2} \mathrm{O}} \times \mathrm{IEC}_{\mathrm{w}}},
$$

where $M_{\mathrm{H}_{2} \mathrm{O}}$ is the molar mass of water.

\section{Ion transport properties and VRFB performance}

$\mathbf{V O}^{2+}$ permeability. The $\mathrm{VO}^{2+}$ permeability of membranes was determined using a diffusion test as described elsewhere. ${ }^{23}$ The prepared membrane with an effective area of $1.76 \mathrm{~cm}^{2}$ was placed between two diffusion half cells. $11 \mathrm{~mL}$ of $1 \mathrm{M} \mathrm{VOSO}_{4}$ in $2 \mathrm{M} \mathrm{H}_{2} \mathrm{SO}_{4}$ solution was injected into one side of the diffusion cell (feed side). To balance the osmotic pressure across the membrane, the same amount of $1 \mathrm{M} \mathrm{MgSO}_{4}$ in $2 \mathrm{M} \mathrm{H}_{2} \mathrm{SO}_{4}$ solution was injected into the other side of the cell (permeate side). The solution in both diffusion cells was continuously stirred with magnetic stirrers during the test to mitigate concentration polarization. The $\mathrm{VO}^{2+}$ concentration at the permeant side was monitored using UV-Vis spectroscopy (UV-1800, Shimadzu, Japan) at a regular interval. The $\mathrm{VO}^{2+}$ permeability through the membrane was calculated using the following formula:

$$
V \frac{\mathrm{d} C_{\mathrm{B}}(t)}{\mathrm{d} t}=A \frac{P}{L}\left(C_{\mathrm{A}}-C_{\mathrm{B}}(t)\right),
$$

where $V$ is the volume of solution in each reservoir, $C_{\mathrm{A}}$ is the feed side $\mathrm{VO}^{2+}$ ion concentration, $C_{\mathrm{B}}$ is the permeation side $\mathrm{VO}^{2+}$ ion concentration, $t$ is the testing time, $A$ is the effective membrane area, $P$ is the $\mathrm{VO}^{2+}$ ion permeability, and $L$ is the membrane thickness.

Proton conductivity and area resistance. The in-plane ionic conductivity was measured via the electrochemical impedance spectroscopy (EIS) method using a Metrohm potentiostat/ galvanostat (Metrohm, FL, USA). The frequency range adopted for the conductivity test was $10^{6} \mathrm{~Hz}$ to $10 \mathrm{~Hz}$ and the amplitude was $10 \mathrm{mV}$. Before the proton conductivity test, all membranes were immersed in deionized water for 24 hours. The proton conductivity was calculated from the resistance value obtained by extrapolating the low-frequency curve on the Nyquist plot based on the following equation:

$$
\sigma=\frac{L}{R \cdot A}
$$

where $L$ corresponds to the electrode separation, $R$ is the membrane resistance and $A$ is the membrane cross-sectional area. For the area resistance measurement, the conductivity cell 
was setup using the method described in the literature. ${ }^{52}$ The resistance of the entire cell with $\left(R_{\text {tot }}\right)$ and without the membrane $\left(R_{\text {blank }}\right)$ was determined using EIS over a frequency range from $10^{6} \mathrm{~Hz}$ to $10 \mathrm{~Hz}$ with an amplitude of $10 \mathrm{mV}$. The area resistance of the membrane was calculated from the difference between the two values $\left(R_{\text {tot }}-R_{\text {blank }}\right)$.

Activation energy measurement. The permeation activation energy of vanadium ions in Nafion and BP-ArF4 was obtained from the Arrhenius plot (Fig. S12, ESI $\dagger$ ). The vanadium permeability and temperature follow an Arrhenius like relation (eqn (6)). To measure the vanadium permeation activation energy, the $\mathrm{VO}^{2+}$ permeability test was performed at different temperatures for each membrane inside a temperature-control chamber. From all the experiments, it was found that $\log (D)$ is linearly correlated with $1 /(R T)$. As suggested by eqn (6), activation energy (Table S2, ESI $\dagger$ ) was obtained from the slope of the $\log (D)$ vs. $1 /(R T)$ plot. $^{53}$

It is worth mentioning that a membrane has different swelling ratio at different temperatures. Hence, a change in membrane dimension was considered during calculating membrane permeability at each temperature. The activation energies of Nafion 117, Nafion 212, and BP-ArF4 are listed in Table S2 (ESI $\dagger$ ). The temperature dependence of the vanadium permeability of Nafion 117, Nafion 212, and BP-ArF4 is displayed in Fig. S9 (ESI $\dagger$ ).

$$
D=D_{0} \exp \left(-\frac{E}{R T}\right),
$$

where $D$ is the vanadium permeability/diffusivity $\left(\mathrm{cm}^{2} \mathrm{~min}^{-1}\right)$, $D_{0}$ is the pre-exponential factor $\left(\mathrm{cm}^{2} \mathrm{~min}^{-1}\right), E$ is the activation energy $\left(\mathrm{kJ} \mathrm{mol}^{-1}\right), R$ is the universal gas constant $\left(8.314 \mathrm{~J} \mathrm{~mol}^{-1} \mathrm{~K}^{-1}\right)$, and $T$ is the absolute temperature $(\mathrm{K})$.

VRFB single cell test. The configuration of the VRFB cell has been reported previously. ${ }^{54}$ Two graphite felts (MTI, $30 \times 30 \times$ $4 \mathrm{~mm}$ ) were used as electrodes without any post-treatment. The testing membrane was sandwiched between the two graphite felts with an active area of $9 \mathrm{~cm}^{2}$. Two copper current collectors were coated with gold to prevent corrosion. The gold coated copper plates were separated from carbon felts by two TF6 SIGRACELL ${ }^{\circledR}$ bipolar plates (SGL Carbon, USA). The same volume of electrolytes (each $45 \mathrm{~mL}$ ) containing $1.6 \mathrm{M}$ vanadium ions and $4 \mathrm{M} \mathrm{H}_{2} \mathrm{SO}_{4}$ were adopted as the catholyte and anolyte solutions. The catholyte was prepared by oxidizing V(Iv) to V(v) ions under galvanostatic conditions, and the anolyte was prepared by reducing V(IV) to V(II). During the battery operation, the half-cell reaction on the positive electrode was $\mathrm{V}(\mathrm{Iv}) \rightleftharpoons \mathrm{V}(\mathrm{v})+\mathrm{e}^{-}$, and the reaction on the negative electrode was $\mathrm{V}(\mathrm{III})+\mathrm{e}^{-} \rightleftharpoons \mathrm{V}(\mathrm{II}) .^{55}$ The electrolytes were circulated using Masterflex L/S peristaltic pumps (Cole-palmer, USA) with the flow rate of $30 \mathrm{~mL} \mathrm{~min}{ }^{-1}$. The operation of the cell was controlled using a CT2001A-5V1.8A battery testing system (Landt, China) with the cut-off voltage of $1.65 \mathrm{~V}$ (charge process) and $0.8 \mathrm{~V}$ (discharge process), respectively. Coulombic efficiency (CE), voltage efficiency (VE) and energy efficiency (EE) of VRFB were calculated using the following equations:

$$
\text { Coulombic efficiency (CE), } \%=\frac{t_{\text {Discharge }}}{t_{\text {Charge }}} \times 100 \% \text {, }
$$

$$
\begin{gathered}
\text { Voltage efficiency (VE), } \%=\frac{V_{\text {Discharge }}}{V_{\text {Charge }}} \times 100 \%, \\
\text { Energy efficiency }(\mathrm{EE}), \%=\frac{\mathrm{CE} \times \mathrm{VE}}{100},
\end{gathered}
$$

Oxidative stability. The oxidative stability of the membranes against $\mathrm{V}(\mathrm{v})$ species was tested according to a method widely reported in the literature. ${ }^{56-58}$ Prior to the test, the membranes were dried in vacuo for one day. Afterwards, $0.12 \mathrm{~g}$ (dry weight) of membrane sample was immersed in $10 \mathrm{~mL}$ of $0.1 \mathrm{M} \mathrm{V}(\mathrm{v}) / 4 \mathrm{M}$ $\mathrm{H}_{2} \mathrm{SO}_{4}$ solution, which is prepared from the fully charged catholyte solution. The concentration of V(IV) species in the solution, which is generated due to the oxidation of the membranes, was monitored using a UV-Vis spectrophotometer (UV-1800, Shimadzu, Japan). The as-prepared 0.1 M V(v)/4 M $\mathrm{H}_{2} \mathrm{SO}_{4}$ solution was used as the blank reference for the measurements. The use of a diluted V(v) solution instead of highly concentrated battery testing solution is considered for the measuring range of UV-vis. The stability result can be found in Fig. S5 (ESI $\dagger$ ).

Small angle X-ray scattering. Small angle X-ray scattering (SAXS) was carried out using a home-built camera using a rotating anode (Bruker FR591-Nonius) operating at $3 \mathrm{~kW}$ with a source of $\mathrm{Cu}-\mathrm{K} \alpha$ radiation $(\lambda=1.5418 \AA)$. The X-ray optics consists of a set of two horizontal and vertical $16 \mathrm{~cm}$ long Ni-filtered total reflection mirrors (Kirkpatrick-Baez mirrors) positioned at $180 \mathrm{~cm}$ from the X-ray source. The size of the source $\left(0.2 \times 0.2 \mathrm{~mm}^{2}\right)$ and its distance from the X-ray optics $(180 \mathrm{~cm})$ provide a low divergence of the X-ray beam ( $0.05 \mathrm{mrad})$, which is a key parameter (with the high-brightness) to optimize the SAXS and GISAXS applications.

The beam line is equipped with a set of 4 beam defining slits (close to mirror optics) and a set of 4 anti-scattering slits in front of the sample position (Xenocs motorized non-scattering slits). The distance between the two sets of slits is $180 \mathrm{~cm}$, thus providing very low-background intensity even at low scattering angle. Scattering patterns were recorded using a twodimensional $14 \times 14 \mathrm{~cm}^{2}$ area (Bruker VANTEC-2000) mikroGap $^{\circledR}$ detector. The mikroGap ${ }^{\circledR}$ technology gives a very fine Point Spread Function which allows the measurement of even weak scattering intensities close to strong diffraction peaks with pixel size resolution of either $70 \mu \mathrm{m}, 140 \mu \mathrm{m}$ or $280 \mu \mathrm{m}$. The flux on the sample is $\sim 3 \times 10^{7} \mathrm{ph} \mathrm{s}^{-1}$ with a beam size (FWHM) $\sim 600 \times 600 \mu \mathrm{m}^{2}$. The sample detector distance was placed at $1 \mathrm{~m}$ and $3.5 \mathrm{~m}$ to explore $q$ values from about $q=0.01$ up to $0.4 \AA^{-1}$, where $q$ is the momentum transfer $q=(4 \pi \sin \theta) / \lambda$ and $2 \theta$ is the total scattering angle. The sample-detector distance was calibrated using silver behenate as the standard. The normalization of the scattering data was applied by first measuring the transmission with a semi-transparent beam stop, followed by the thickness of each sample, and finally using a Lupolen sample as the calibrating sample. After equilibration in pure water or in a $1.6 \mathrm{M} \mathrm{VOSO}_{4} / 4 \mathrm{M} \mathrm{H}_{2} \mathrm{SO}_{4}$ aqueous solution, two or three membrane samples with $4 \mathrm{~mm}$ diameter (total thickness around $300 \mu \mathrm{m}$ ) were placed in a brass cell 
between $5 \mu \mathrm{m}$ thick Mylar sheets serving as windows. The mass difference of the membranes in the dry proton and the soaked state was attributed to electrolyte uptake. For calculating the volume fraction of vanadium electrolyte in the membrane, its density was taken to be identical to that of the $1.6 \mathrm{M} \mathrm{VOSO}_{4} / 4 \mathrm{M}$ $\mathrm{H}_{2} \mathrm{SO}_{4}$ aqueous solution $\left(1.4 \mathrm{~g} \mathrm{~cm}^{-3}\right)$.

Density functional theory (DFT) calculations. For density functional theory (DFT) calculations, we employed the $\omega$ B97XD functional $^{59}$ and $6-31 \mathrm{G}(\mathrm{d}, \mathrm{p})$ basis sets for $\mathrm{S}, \mathrm{N}, \mathrm{C}, \mathrm{H}$, and $\mathrm{O}$ atoms. ${ }^{60,61}$ For vanadium, core electrons were represented using the LANL08 effective core potential (ECP) and for valence electrons of vanadium, we used LANL08 basis sets augmented by $f$ function. ${ }^{62-64}$ Geometry optimizations and additional frequency calculations to confirm that the optimized structure is a minimum were conducted using the Gaussian 16 program.

\section{Conflicts of interest}

The authors declare no competing interests.

\section{Acknowledgements}

This work was supported by grants from the National Science Foundation (grant No. CBET-1706910 with Dr Christina Payne as program manager), the U.S. Department of Energy, Office of Efficiency and Renewable Energy (EERE), Fuel Cell Technology Office (FCTO), Award No. DE-EE0007647 (Program manager: Neha Rustagi), ARPA-E (IONICS DE-AR0000769 and REFUEL DEAR0000805), and New York State Energy Research and Development Authority (NYSERDA; grant No. 127734). T. Wang acknowledges support from the UIC Provost's Graduate Research Award program. S. Kim and C. Bae thank StorEn for discussions.

\section{Notes and references}

1 C. H. Park, C. H. Lee, M. D. Guiver and Y. M. Lee, Prog. Polym. Sci., 2011, 36, 1443-1498.

2 R. M. Darling, K. G. Gallagher, J. A. Kowalski, S. Ha and F. R. Brushett, Energy Environ. Sci., 2014, 7, 3459-3477.

3 M. Skyllas-Kazacos, M. H. Chakrabarti, S. A. Hajimolana, F. S. Mjalli and M. Saleem, J. Electrochem. Soc., 2011, 158, R55-R79.

4 B. E. Logan and M. Elimelech, Nature, 2012, 488, 313-319.

5 G. M. Geise, M. A. Hickner and B. E. Logan, ACS Appl. Mater. Interfaces, 2013, 5, 10294-10301.

6 P. Długołęcki, K. Nymeijer, S. Metz and M. Wessling, J. Membr. Sci., 2008, 319, 214-222.

7 B. Dunn, H. Kamath and J.-M. Tarascon, Science, 2011, 334, 928-935.

8 W. Wang, Q. Luo, B. Li, X. Wei, L. Li and Z. Yang, Adv. Funct. Mater., 2013, 23, 970-986.

9 K. Lin, R. Gómez-Bombarelli, E. S. Beh, L. Tong, Q. Chen, A. Valle, A. Aspuru-Guzik, M. J. Aziz and R. G. Gordon, Nat. Energy, 2016, 1, 16102.

10 W. Wang and V. Sprenkle, Nat. Chem., 2016, 8, 204.
11 B. Huskinson, M. P. Marshak, C. Suh, S. Er, M. R. Gerhardt, C. J. Galvin, X. Chen, A. Aspuru-Guzik, R. G. Gordon and M. J. Aziz, Nature, 2014, 505, 195.

12 N. Wang, J. Yu, Z. Zhou, D. Fang, S. Liu and Y. Liu, J. Membr. Sci., 2013, 437, 114-121.

13 S. Roe, C. Menictas and M. Skyllas-Kazacos, J. Electrochem. Soc., 2016, 163, A5023-A5028.

14 X. Li, H. Zhang, Z. Mai, H. Zhang and I. Vankelecom, Energy Environ. Sci., 2011, 4, 1147-1160.

15 X. Wei, Z. Nie, Q. Luo, B. Li, B. Chen, K. Simmons, V. Sprenkle and W. Wang, Adv. Energy Mater., 2013, 3, 1215-1220.

16 M. Ulaganathan, V. Aravindan, Q. Yan, S. Madhavi, M. SkyllasKazacos and T. M. Lim, Adv. Mater. Interfaces, 2016, 3, 1500309.

17 S.-H. Cha, J. Nanomater., 2015, 2015, 207525.

18 Q. Luo, H. Zhang, J. Chen, P. Qian and Y. Zhai, J. Membr. Sci., 2008, 311, 98-103.

19 J. Xi, Z. Wu, X. Qiu and L. Chen, J. Power Sources, 2007, 166, 531-536.

20 X. Teng, Y. Zhao, J. Xi, Z. Wu, X. Qiu and L. Chen, J. Membr. Sci., 2009, 341, 149-154.

21 M. A. Aziz and S. Shanmugam, J. Power Sources, 2017, 337, 36-44.

22 S.-H. Cha, J. Nanomater., 2015, 2015, 1.

23 D. Chen, M. A. Hickner, E. Agar and E. C. Kumbur, Electrochem. Commun., 2013, 26, 37-40.

24 Z. Li, W. Dai, L. Yu, J. Xi, X. Qiu and L. Chen, J. Power Sources, 2014, 257, 221-229.

25 Q. Dai, Z. Liu, L. Huang, C. Wang, Y. Zhao, Q. Fu, A. Zheng, H. Zhang and X. Li, Nat. Commun., 2020, 11, 1-9.

26 Y. Zeng, L. Wang, L. Zhang and J. Q. Yu, J. Membr. Sci., 2018, 546, 225-233.

27 A. Buonerba, V. Speranza and A. Grassi, Macromolecules, 2013, 46, 778-784.

28 W.-H. Lee, E. J. Park, J. Han, D. W. Shin, Y. S. Kim and C. Bae, ACS Macro Lett., 2017, 6, 566-570.

29 X. Ling, C. Jia, J. Liu and C. Yan, J. Membr. Sci., 2012, 415-416, 306-312.

30 M. S. Cha, H. Y. Jeong, H. Y. Shin, S. H. Hong, T.-H. Kim, S.-G. Oh, J. Y. Lee and Y. T. Hong, J. Power Sources, 2017, 363, 78-86.

31 B. Zhang, S. Zhang, D. Xing, R. Han, C. Yin and X. Jian, J. Power Sources, 2012, 217, 296-302.

32 J. Si, Y. Lv, S. Lu and Y. Xiang, J. Power Sources, 2019, 428, 88-92.

33 D. Chen, M. A. Hickner, E. Agar and E. C. Kumbur, J. Membr. Sci., 2013, 437, 108-113.

34 B. Jiang, L. Wu, L. Yu, X. Qiu and J. Xi, J. Membr. Sci., 2016, 510, 18-26.

35 C. Li, A. L. Ward, S. E. Doris, T. A. Pascal, D. Prendergast and B. A. Helms, Nano Lett., 2015, 15, 5724-5729.

36 D. You, H. Zhang, C. Sun and X. Ma, J. Power Sources, 2011, 196, 1578-1585.

37 O. Nibel, S. M. Taylor, A. Pătru, E. Fabbri, L. Gubler and T. J. Schmidt, J. Chem. Soc., Faraday Trans., 2017, 164, A1608.

38 I. Derr, M. Bruns, J. Langner, A. Fetyan, J. Melke and C. Roth, J. Power Sources, 2016, 325, 351-359. 
39 C. H. Park, S. Y. Lee, D. S. Hwang, D. W. Shin, D. H. Cho, K. H. Lee, T.-W. Kim, T.-W. Kim, M. Lee and D.-S. Kim, Nature, 2016, 532, 480-483.

40 A. Münchinger and K.-D. Kreuer, J. Membr. Sci., 2019, 592, 117372.

41 A. Münchinger, T. Wang, S. Kim and K.-D. Kreuer, 2019, in preparation.

42 I. S. Chae, T. Luo, G. H. Moon, W. Ogieglo, Y. S. Kang and M. Wessling, Adv. Energy Mater., 2016, 6, 1600517.

43 K.-D. Kreuer, S. J. Paddison, E. Spohr and M. Schuster, Chem. Rev., 2004, 104, 4637-4678.

44 K. D. Kreuer and G. Portale, Adv. Funct. Mater., 2013, 23, 5390-5397.

45 K. R. Hinkle, C. J. Jameson and S. Murad, J. Phys. Chem. C, 2014, 118, 23803-23810.

46 X. Wu, J. Wang, S. Liu, X. Wu and S. Li, Electrochim. Acta, 2011, 56, 10197-10203.

47 C. Choi, S. Kim, R. Kim, Y. Choi, S. Kim, H.-y. Jung, J. H. Yang and H.-T. Kim, Renewable Sustainable Energy Rev., 2017, 69, 263-274.

48 H.-J. Schneider, Chem. Sci., 2012, 3, 1381-1394.

49 Q. Dai, Z. Liu, L. Huang, C. Wang, Y. Zhao, Q. Fu, A. Zheng, H. Zhang and X. Li, Nat. Commun., 2020, 11, 13.

50 W.-H. Lee, Y. S. Kim and C. Bae, ACS Macro Lett., 2015, 4, 814-818.

51 L. Assumma, C. Iojoiu, R. Mercier, S. Lyonnard, H. D. Nguyen and E. Planes, J. Polym. Sci., Part A: Polym. Chem., 2015, 53, 1941-1956.
52 G.-J. Hwang and H. Ohya, J. Membr. Sci., 1996, 120, 55-67.

53 J. Tolliday, E. Woods and E. Hartung, Trans. Faraday Soc., 1949, 45, 148-155.

54 T. Wang, S. J. Moon, D.-S. Hwang, H. Park, J. Lee, S. Kim, Y. M. Lee and S. Kim, J. Membr. Sci., 2019, 583, 16-22.

55 M. Rychcik and M. Skyllas-Kazacos, J. Power Sources, 1988, 22, 59-67.

56 M. S. Cha, S. W. Jo, S. H. Han, S. H. Hong, S. So, T.-H. Kim, S.-G. Oh, Y. T. Hong and J. Y. Lee, J. Power Sources, 2019, 413, 158-166.

57 S. Kim, T. B. Tighe, B. Schwenzer, J. Yan, J. Zhang, J. Liu, Z. Yang and M. A. Hickner, J. Appl. Electrochem., 2011, 41, 1201-1213.

58 T. Mohammadi and M. S. Kazacos, J. Appl. Electrochem., 1997, 27, 153-160.

59 J.-D. Chai and M. Head-Gordon, Phys. Chem. Chem. Phys., 2008, 10, 6615-6620.

60 A. McLean and G. Chandler, J. Chem. Phys., 1980, 72, 5639-5648.

61 M. M. Francl, W. J. Pietro, W. J. Hehre, J. S. Binkley, M. S. Gordon, D. J. DeFrees and J. A. Pople, J. Chem. Phys., 1982, 77, 3654-3665.

62 P. J. Hay and W. R. Wadt, J. Chem. Phys., 1985, 82, 299-310.

63 L. E. Roy, P. J. Hay and R. L. Martin, J. Chem. Theory Comput., 2008, 4, 1029-1031.

64 A. Ehlers, M. Böhme, S. Dapprich, A. Gobbi, A. Höllwarth, V. Jonas, K. Köhler, R. Stegmann, A. Veldkamp and G. Frenking, Chem. Phys. Lett., 1993, 208, 111-114. 